Sustainable Structures

ISSN: 2789-3111 (Print); ISSN: 2789-312X (Online)

http://www.sustain-dpl.com/picnews.asp?id=155

DOI: $10.54113 / j$.sust.2021.000003

ORIGINAL ARTICLE

\title{
Material characterization and structural response under earthquake loads of hakka rammed earth buildings
}

\author{
Ruifeng Liang *, Daniel Stanislawski, Gangarao Hota \\ NSF Center for Integration of Composites into Infrastructure and Constructed Facilities Center, West Virginia University, \\ Morgantown, WV 26506, USA. \\ *Corresponding Author: Ray Liang, Email: rliang@mail.wvu.edu
}

\begin{abstract}
Hakka Tulou are rammed earth buildings that have survived material aging, natural weathering and earthquakes for hundreds of years. Previous paper has reported our observations and findings from nondestructive evaluations in field with focus on the integrity of the rammed earth outer walls and inner timber structures as well as the thermal comfort of living in these buildings. This paper presents the structural response of Tulou buildings under earthquake loads using material data from field and employing finite element (FE) analysis program. The material characterization included scanning electron microscopy and compression strength/modulus of rammed earth samples and wall reinforcements, revealing their high strength and durability. The FE analyses were conducted on unreinforced Huanji Tulou as per the simplified lateral force analysis procedure defined by the Code ASCE-7 under three types of wall conditions: 1) unreinforced rammed earth outer wall only, 2) reinforced rammed earth outer wall without inner wooden structures, and 3) unreinforced rammed earth outer wall with inner wooden structures. The FE modeling revealed that the existing large crack in the outer earth wall of Huanji Tulou would not have developed under a strong earthquake load if the earth walls were reinforced. Furthermore, the high volume rammed earth wall integrated with inner timber structures would have offered the building unique earthquake resistance.
\end{abstract}

Keywords: Hakka Tulou; rammed earth; reinforced rammed earth; finite element analysis; earthquake resistance; structural response; ASCE-7; selfhealing of crack; Huanji Tulou

\section{Introduction}

Hurricane Katrina (United States) in 2005 and Great Sichuan Earthquake (China) in 2008 have led the engineering community to explore more disaster-resistant residential, commercial and other vital public structures. The round residential houses built by Deltec Homes are reported to be much more hurricane resistant than conventional houses [2]. When Hurricane Katrina struck the Gulf Coast in 2005, none of the Deltec homes suffered any structural damage from Katrina's category 5 hurricane force winds, because there was not enough surface area on any part of a round house for pressure to build up. In addition, their less exposed surface area with no re-entrant corners than square houses offers superior

000003-1 
energy efficiency and improved durability including stability to earthquake forces [2]. The addition of giant historic round houses of Fujian Province of China (known as Hakka Tulou) into the World Heritage sites [3] has stimulated the authors' interest to take an in-depth investigation of "the-only-oneof-its-kind" structures with emphasis on their earthquake resistance, as one of the research objectives [1]. This work was sponsored by the National Science Foundation of the United States of America.

Hakka Tulou buildings were constructed with rammed earth and other local materials using adaptable technology. Each building has thick $(\sim 2 \mathrm{~m})$ outer rammed earth walls and inner timber structures that make up floors and partition rooms. They are three to five stories in height and round or square in shape; some of these buildings have several hundred rooms capable of housing a large number of families. These buildings have survived several major earthquakes of magnitudes 5 or higher on the Richter scale since the 11th century and also numerous typhoons and floods; however, some buildings might have cracks in their walls and broken roof tiles [3, 4]. Locals have been using Huanji Tulou (built in 1693) as an example to illustrate the Tulou's superior earthquake resistance. It is broadly reported that there was a strong earthquake (7.0 Richter scale) in the area in 1918 resulting in a crack measuring $20 \mathrm{~cm}$ in width and 3 meters in length on the outer rammed earth wall of Huanji Tulou. The locals claim that the crack had self-healed subsequently $[5,6]$.

The authors closely examined the reported crack of Huanji Tulou during the field study in the summer of 2009 and further conducted finite element (FE) analyses including earthquake loads as per design code ASCE-7 to understand how and why this crack was formed and self-healed [7]. One postulation for the self-healing phenomenon is that the massive rammed earth wall system integration with inner wooden structures might have contributed to self-healing.

The above mentioned FE work was carried out using the strength and modulus data of the constituent materials of the rammed earth wall including rammed earth, wooden and bamboo reinforcement. These data were obtained from the material characterization of the field-collected samples from five different Tulou buildings. Surprisingly, Hakka knew how to use wooden or bamboo sticks to reinforce rammed earth walls hundreds of years ago. The volume fraction of such reinforcements in a typical rammed earth wall was determined from the field measurements of an exposed wall section. Through volume fraction numbers, the modulus of elasticity of the reinforced rammed earth wall was computed using the Rule of Mixture along with the constituent material property data.

\section{Hakka Tulou Buildings Studied}

There are many shapes of Tulou ('Tu' meaning earth, 'lou" meaning building), but square and round Tulous are most common. In Yongding County of Fujian Province of China alone, there are 4,000 square Tulous and 360 round Tulous. Round Tulous were developed as an improvement of square Tulous for better functions and durability [8]. The Tulou buildings selected for the field study by the authors are listed in our previous paper [1]. They are all located in Yongding County and represent a range of Hakka Tulou structures of different ages built in: 1) $8^{\text {th }}$ century; 2) $15^{\text {th }}$ century; 3) $17^{\text {th }}$ century; and 4) $20^{\text {th }}$ century so that the evolutions of material selection, structural design and construction from $8^{\text {th }}$ to $20^{\text {th }}$ century were evaluated. A brief description of each Tulou building is given herein including its age. For example, wooden specimen from Chengqi Tulou was tested for its radiocarbon dating age. The carbon dating test result agrees surprisingly well with the record completion date of 1709 of Chengqi Tulou [1].

\subsection{Fuxing Tulou}

Fuxing Tulou is located in Hulei Town. Fuxing is the oldest square Tulou of two stories, built in 769 (Tang dynasty of China). Half of the structure was burned in a 1852 war, while the other half is still in use by eight families (Fig. 1). The earth wall was not reinforced with wood chips but built of a 
composite material known as "Sanhetu" that is a mixture of red clay, lime, and pebbles. The authors even found large stones inside its earth wall as shown in the insert of Fig. 1. The owner told the authors that in 1970's it took 16 days for two people to make an opening for a window and 40 days for a side door, illustrating how strong the wall is even after aging for 1200 years. Nondestructive evaluations (NDE) using infrared thermography, rebound hammer and ultrasonic testing were conducted on this building during field study and its earth wall samples were collected for laboratory testing.


Fig. 1. Fuxing Tulou and its earth wall

\subsection{Wuyun Tulou}

Wuyun Tulou, located in Gaobei Village of Gaotou Town, is a square Tulou with four stories. Its front wall has some cracks and is buckling inward at the center section (Fig. 2). Several elders are living inside. Built around 1500 (Ming Dynasty), this is one of the oldest known rammed earth buildings in this village. The earth wall was found with wood chips as reinforcement. NDE testing was conducted on the earth walls during field study and the results were reported in [1]. Its earth wall samples were collected for laboratory evaluation and the data are presented in Section 3 of this paper.

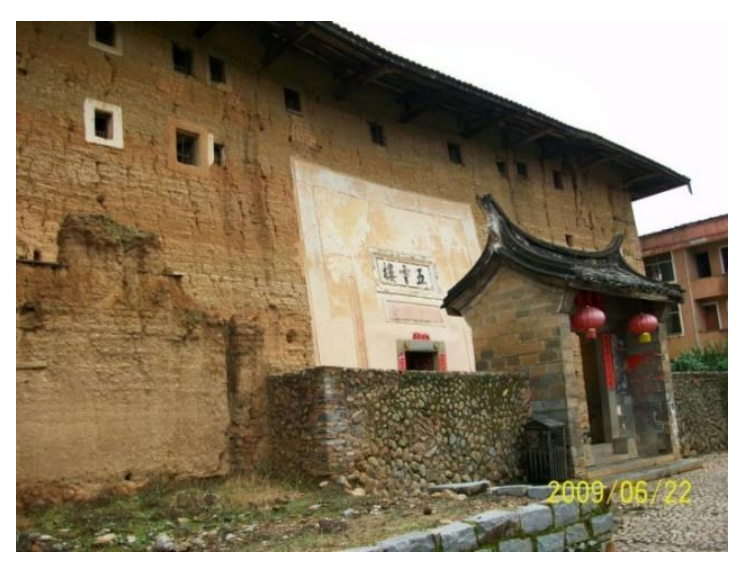

Fig. 2. Wuyun Square Tulou

\subsection{Chengqi Tulou}

Chengqi Tulou is also located in Gaobei village of Gaotou Town, in the neighborhood of Wuyun Tulou. Chengqi is well known as the King of Tulou (Fig.s 3). This building is four story in height and has a diameter of $73 \mathrm{~m}$. Inside the main building there are four rings of one story buildings with the center being the ancestral shrine. There are two wells for water supply and three gates as exits. The construction of the building took about 50 years (from 1662 to 1709). This complex has 400 rooms. At its maximum, it accommodated 80 families of 800 people. Currently 60 families are still living there. 
Because of its remarkable scale and multi-ring structure, this building was adopted as Chinese stamp pattern since 1986. Load tests of roof truss and floor beams as well as temperature and humidity measurements at various locations were conducted on Chengqi Tulou [1]. Its earth wall was reinforced with wood chips. Rammed earth samples and timber samples were collected and used for laboratory testing including carbon dating for building age.
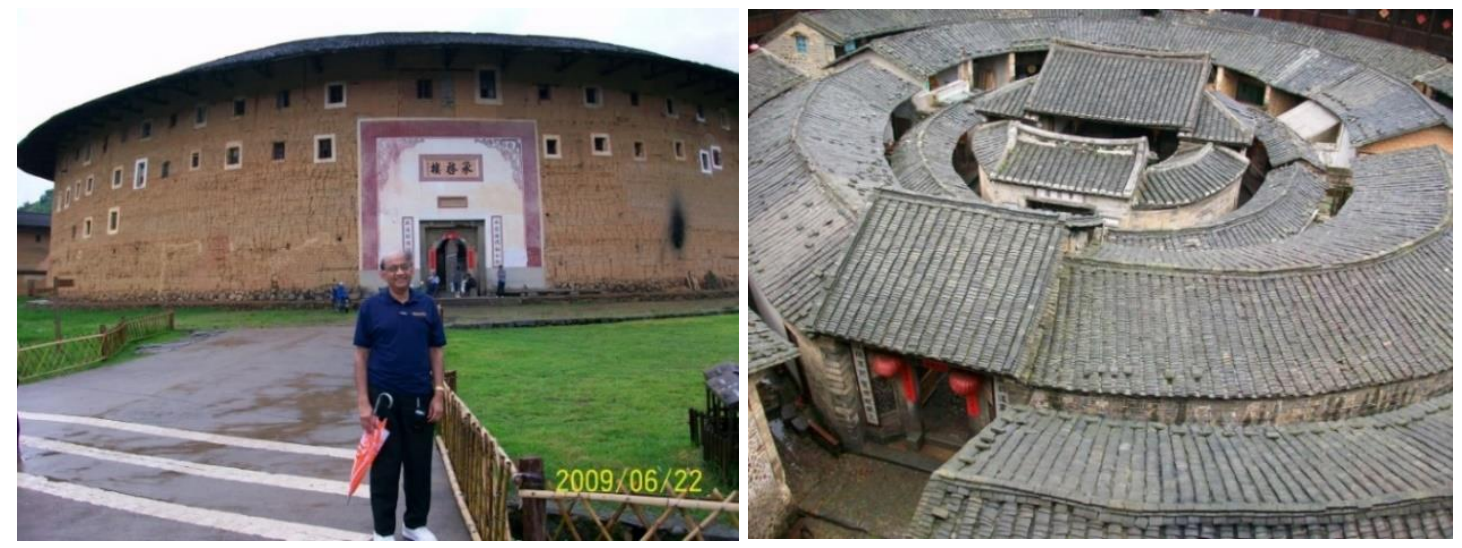

Fig. 3. Outside and Inside Chengqi Tulou

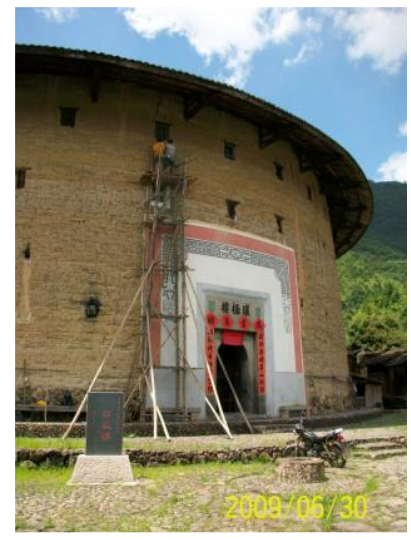

(a)

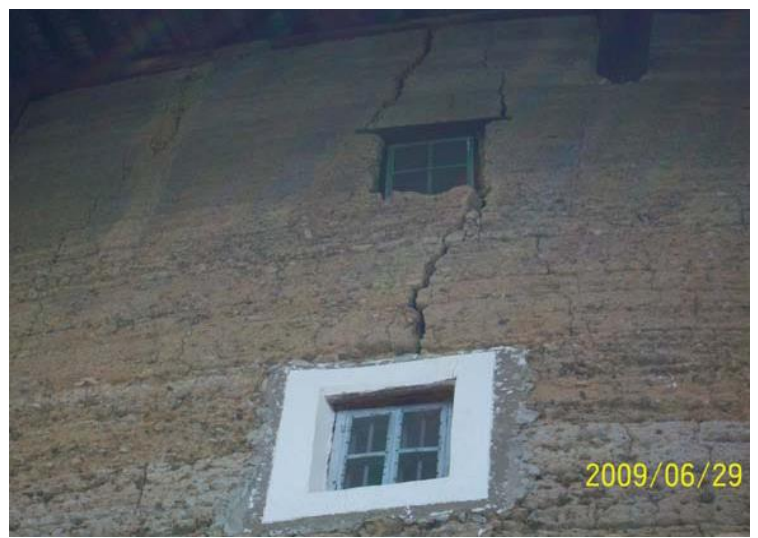

(b)

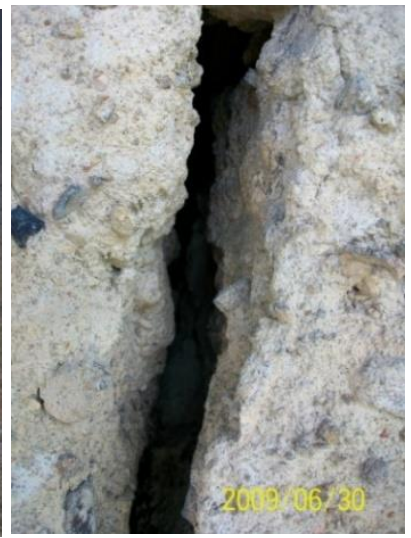

(c)

Fig. 4. Huanji Tulou and its wall crack, a) the crack location with reference to the ground; b) a global view of the crack; c) close-up view of the crack.

\subsection{Huanji Tulou}

Huanji Tulou is located in Nanxi Village of Hukeng Town. It was built in 1693. This building has a diameter of $43.2 \mathrm{~m}$ and is $20 \mathrm{~m}$ in height with four stories (Fig. 4a). The building has two rings of one story buildings. There are 152 rooms, currently housing 21 families and 116 people. Huanjilou was known as the strongest Tulou. The locals claim that a R.7 earthquake in 1918 created a large crack on the wall but later the crack self-healed. The reported earthquake-induced crack is about 10 meter above the ground. A global view of this crack is shown in Fig. 4b. The crack begins from the both ends of the lintel of $4^{\text {th }}$ floor window, with one continuing upwards to the top edge of rammed earth and the other growing downwards and ending at the lintel of $3^{\text {rd }}$ floor window. To access and examine the crack, a stack up platform was constructed using bamboo during the field study in the summer of 2009, as shown in Fig. 4a. After taking measurements including use of a laser distancer to measure its depth, the authors found that the crack was about $3.5 \mathrm{~m}$ in height. The section between $3^{\text {rd }}$ and $4^{\text {th }}$ windows 1 s $1.78 \mathrm{~m}$ in height, 5 to $10 \mathrm{~cm}$ in width, and $93 \mathrm{~cm}$ in depth. As shown in Fig. $4 \mathrm{c}$, this crack was actually across the 
entire wall thickness and most surprisingly, there were no reinforcement ribs inside the rammed earth wall.

\subsection{Zhencheng Tulou}

Zhencheng Tulou, located in Hongkeng Village of Hukeng Town, was known as the Prince of Tulou because of its being relative young (built in 1912, Fig. 5). It is the most magnificent round Tulou, with an area of $5000 \mathrm{~m}^{2}$ and two rings of inner buildings including a two-story ring building inside four story high rammed earth walls. There are 252 rooms ( 6 rooms as school classrooms). Outside the round main building resembled a mud-made fort. Zhencheng was constructed with the Bagua (八卦) idea (6 room/gua). There are fire-resistant walls between two guas, two wells “yin” and “yang” (一阴一阳) for water supply. A stage-like ancestral shrine is at the center of the complex, of both north/south China and Greek architectural features. There are many cultural treasures such as sculptures, mural paintings, antithetical couplets and work of calligraphy within this building. The results of NDE testing from this building were reported in [1] while this paper reports the data of its earth wall samples.

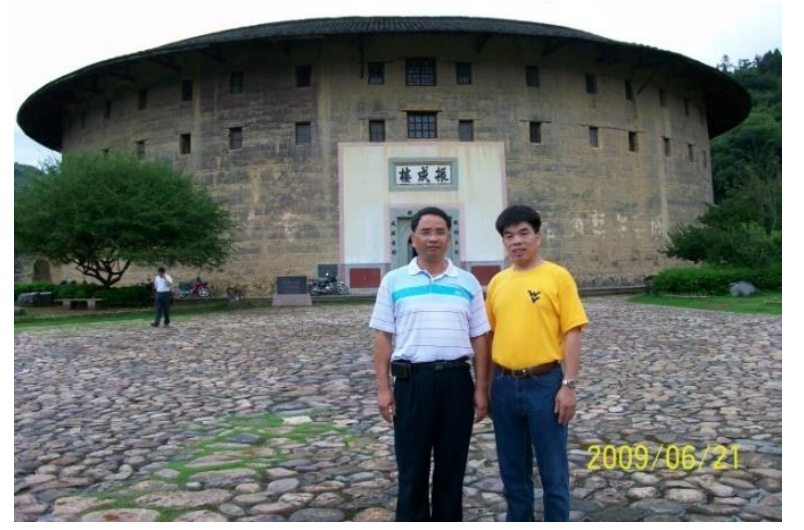

Fig. 5. Zhencheng Tulou

\section{Material Characterization}

Specimens of the constituent materials, including rammed earth, wooden and bamboo reinforcement strips that were used in the Tulou walls for increased strength, were collected from these buildings and tested in the laboratory for their compressive strength and stiffness. The sizes/shapes of these specimens were dictated by the dimensions of field acquired samples, not necessarily in accordance with the specimen requirements of ASTM standards (e.g. ASTM D1633). As a matter of fact, core extracts as per ASTM standard of the rammed earth walls from the Tulou were tried in field but not successful due to the rammed earth becoming brittle under the vibration induced during extraction. The material characterization of earth and timber samples served multi purposes. The first was to establish some baseline compressive strength and stiffness data of the centuries-old materials to compare with present conventional materials, revealing the materials' durability. Secondly, the strength data were used to correlate the results from NDE testing. Finally, these properties were used as inputs in FE modeling. In addition, small pieces of earth samples were also viewed on an advanced Scanning Electron Microscopy (SEM) for morphology and further tested on Energy-dispersive X-ray Spectroscopy (EDS) for the sample's elemental analysis (chemical characterization).

\subsection{SEM and EDS Analysis of Tulou Rammed Earth Samples}

Rammed earth samples were viewed on a Scanning Electron Microscopy (SEM) model Hitachi SEM S-4700 with EDS attachment. The scanning electron microscope provides surface morphology of the earth samples at a micro to near-nano scale allowing us to compare surface property and composition 
among rammed earth samples from different Tulous. Each sample was viewed and photographed at scales of 1mm, 300 micrometer, 200 micrometer, 10 micrometer and 5 micrometer. Fig. 6 shows images for Fuxing and Chengqi Tulou earth samples. After reviewing the SEM images of the earth samples of five buildings, it can be summarized that each of the rammed earth samples looks fairly consistent from one viewing area to another. Except that Fuxing Tulou earth, which is over 1200 years old, has porous morphology (Fig. 6, left), all others (Zhencheng, Chengqi, Wuyun, and Huanji) have mica-like flake surface structures (Fig. 6, right). Chengqi and Wuyun Tulou earth samples have shown presence of wood fibers that were well bonded with surrounding earth (Fig. 7, left) while Fuxing and Zhencheng Tulou earth samples are mixed with stone/rocks (Fig. 7, right).
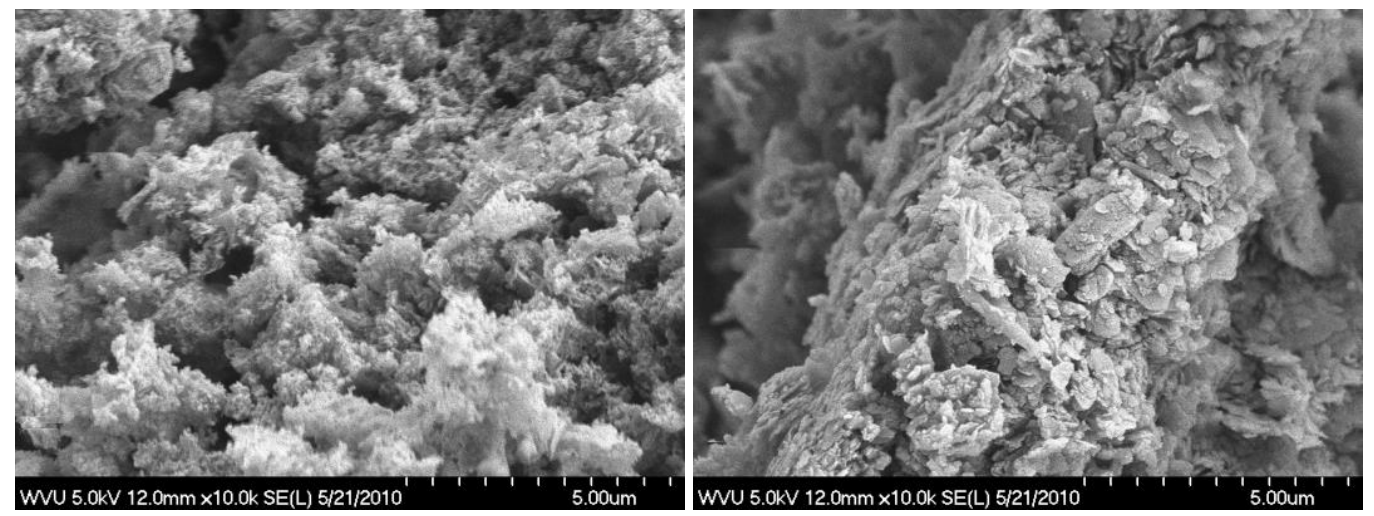

Fig. 6. SEM images of Fuxing (left) and Chengqi (right) earth samples
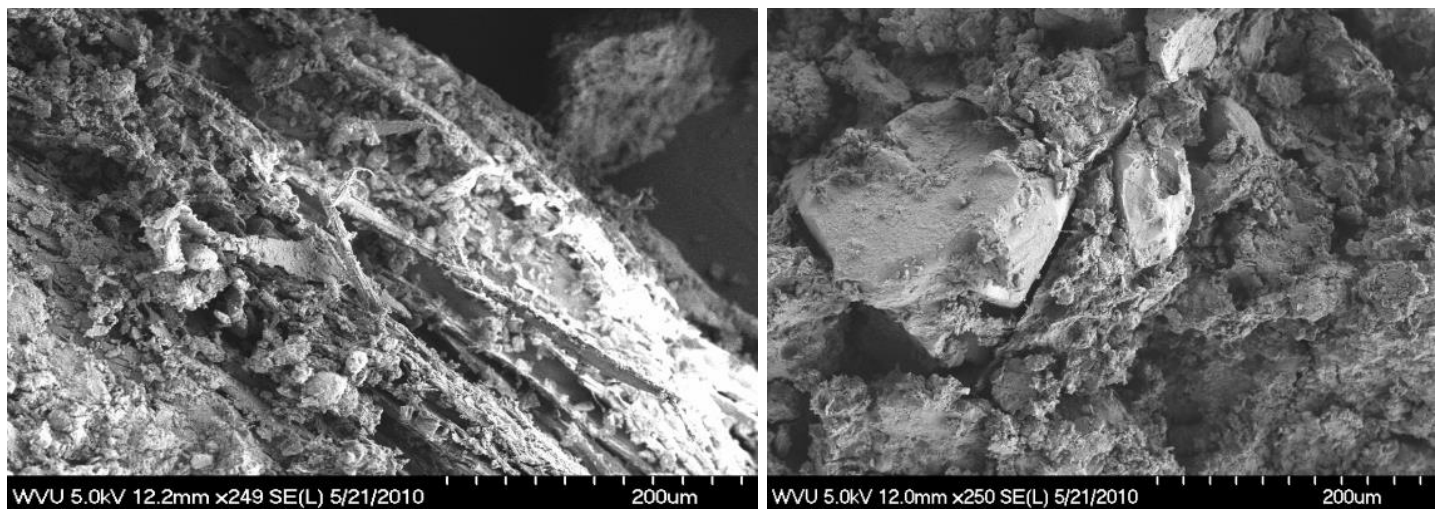

Fig. 7. SEM images of Wuyun (left) and Zhencheng (right) earth samples

Energy-dispersive X-ray Spectroscopy (EDS) analysis can examine the chemical composition of a specimen by showing the amount of existing elements relatively to each other in the form of an elemental spectrum. Overlaid EDS charts for earth samples of five Tulou buildings are shown in Fig. 8. These charts were obtained from relatively pure earth samples, instead of earth samples rich with wood fibers which might yield high carbon peak. From the EDS data one can see that all the samples from the five different Tulou show an abundance in oxygen, silicon, and aluminum (Note that gold in EDS chart comes from specimen preparation coating to make the sample conductive, not present in original earth samples). Three of the five Tulou, Zhencheng, Chengqi, and Wuyun, show an abundance of titanium while Chengqi and Wuyun Tulous also show slightly higher amounts of carbon because of influence of wooden pieces. Even Zhencheng and Fuxing Tulous have phosphorous present whose roles are to be further examined later. As can be seen from the above varying results, the compositions of these samples are unique to what is locally available on site for each of the respective Tulous. This adds the complexity into discussion when comparing the rammed earth wall properties in terms of their varying ages. 


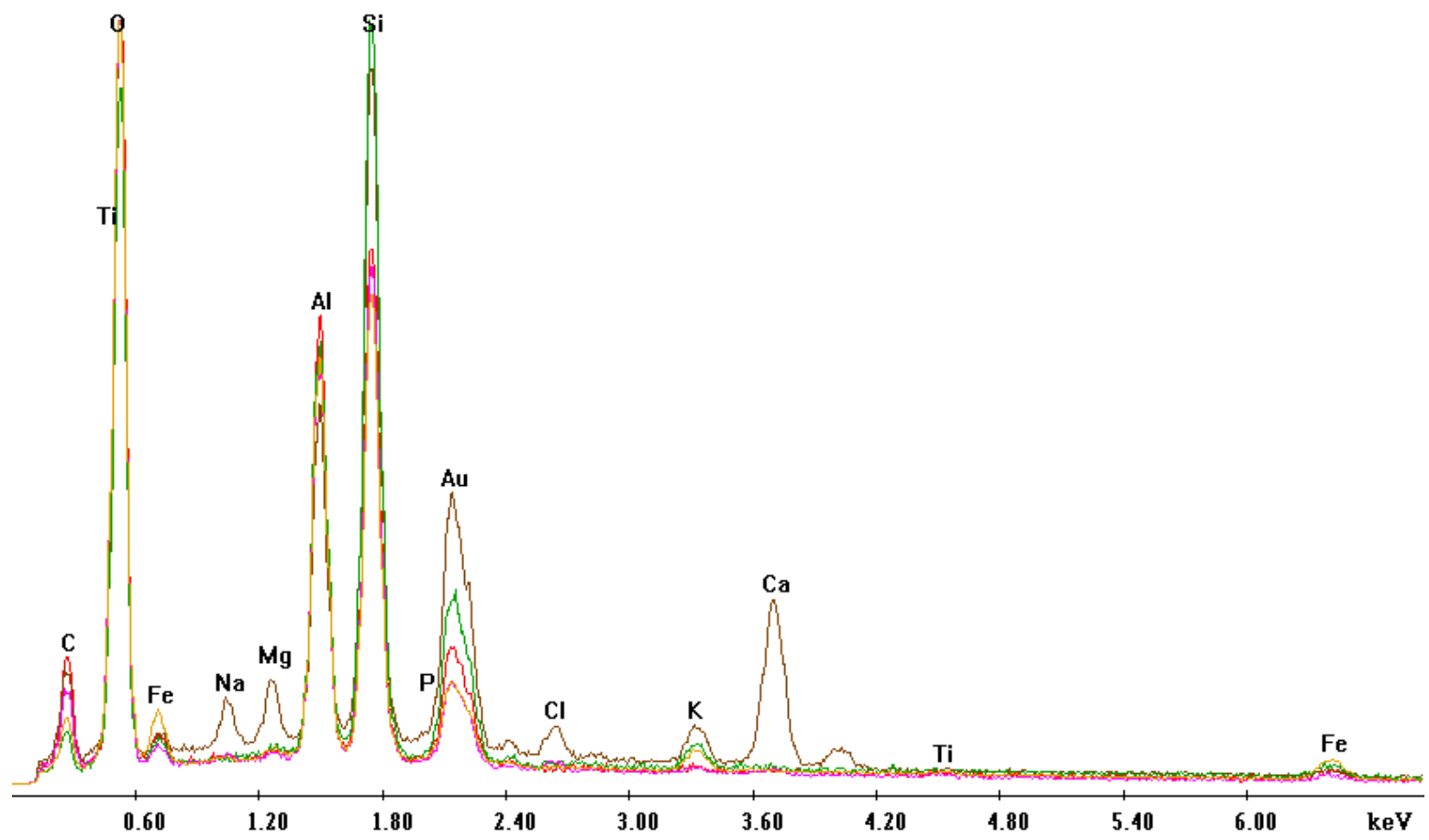

Fig. 8. Overlay EDS charts of earth samples from 5 Tulou buildings

It should be noted that the oldest Fuxing distinguishes its EDS chart from others, revealing an abundant amount of calcium. Calcium comes in lime and subsequently is a constituent material of the walls prepared by the Hakka people. This large amount of calcium in the Fuxing Tulou earth sample explains the high strength of the walls that have survived for over 1240 years. Please note that determination of the mix proportion of rammed earth used in Hakka Tulou is beyond the scope of the present study and readers are referred to other papers for such information $[9,10]$.

\subsection{Compression Properties of Rammed Earth}

Rammed earth specimens were prepared typically in $2.5 \mathrm{~cm} \times 2.5 \mathrm{~cm} \times 5.0 \mathrm{~m}$ rectangular shapes whenever possible from field acquired samples and tested under compression using Instron model 8501 machine. The earth samples are not homogenous in nature. While acquiring samples in field, caution was taken so that earth samples collected did not contain visible rocks/stone/timber. Fig. 9 representatively shows Chengqi Tulou earth sample before and after testing on the test fixture along with resulting stress-strain curve. The strain values were obtained using the direct deformation gage reading from Instron machine's LVDT and dividing by the specimen height. Compression modulus was calculated from the straight line portion of the stress-strain chart, as shown in Fig. 9. Table 1 summarizes the compression properties of the rammed earth samples. Note that testing of Huanji Tulou earth samples did not result in reliable property data because of their brittle nature.

Table 1 shows that the Hakka earth walls have compression strengths ranging from 1.89 MPa to 3.39 MPa (275psi to 490psi). As per a rammed earth engineering specification [11], the earthen building materials industry accepts $2.06 \mathrm{MPa}(300 \mathrm{psi})$ as the minimum compressive strength for rammed earth construction, tested according to ASTM D1633. Hence, these historic rammed earth walls should be 
considered very strong and durable. Since these earth specimens were prepared with restraints from the field collect samples, the results should be on the lower end of their "true" values. More interestingly, both the strength and modulus data appear to show a trend that Hakka earth wall becomes stronger and harder with time. The oldest Fuxing Tulou has a much higher modulus than those of the younger Chengqi and Zhencheng Tulou. This result seems to explain why it was a challenge for the owner of Fuxing to create a new opening. While exploring the reasons why these historic walls are so strong, some articles argued that soupy glutinous rice and brown sugar might be added in the rammed wall material systems that enhance the adhesion and bond among the constituents $[12,13]$. However the owners of Hakka Tulou don't agree with this view point. Our EDS spectrums are not able to verify that statement either. In case of Fuxing Tulou, the rich amount of lime/calcium might have contributed to the fact that the earth wall has become stronger and harder with time.



Fig. 9. Chengqi earth sample before and after compression test and resulting stress/strain curve

Table 1. Rammed earth compression properties

\begin{tabular}{ccccc}
\hline Tulou & $\begin{array}{c}\text { Age } \\
\text { (years) }\end{array}$ & $\begin{array}{c}\text { Test } \\
\text { Replications }\end{array}$ & $\begin{array}{c}\text { Compression } \\
\text { Strength (MPa) }\end{array}$ & $\begin{array}{c}\text { Compression } \\
\text { Modulus (MPa) }\end{array}$ \\
\hline Fuxing & 1240 & 2 & 1.95 & 85.32 \\
Wuyun & 500 & 5 & 3.39 & 83.18 \\
Chengqi & 300 & 2 & 2.84 & 64.14 \\
Huanji & 300 & 1 & $\mathrm{n} / \mathrm{a}$ & $\mathrm{n} / \mathrm{a}$ \\
Zhencheng & 100 & 4 & 1.89 & 58.58 \\
\hline
\end{tabular}




\subsection{Tension and Compression Properties of Wood and Bamboo Samples}

Hakka used bamboo strips and wood branches to reinforce earth walls in the same manner as steel rebars in the modern concrete constructions. These reinforcements, known as wall-ribs, were placed while the wall was being constructed (Fig. 10). Such wooden and bamboo pieces were collected during field study and tested under tension and compression in the laboratory for their mechanical properties. Specimens were cut typically into $2.5 \mathrm{~cm}$ in height for compression test and $12.5 \mathrm{~cm}$ in length for tension test and tested on Instron model 8501 machine. Strain gages model CEA-06-250UW-350 (Vishay Micro-Measurements) were mounted on tension specimens to collect strain data for determination of modulus while under compression, strain values were best obtained using the deformation from Instron machine's LVDT and divided by the specimen height.

Table 2. Mechanical properties of Tulou wood and bamboo samples

\begin{tabular}{clcccc}
\hline Sample Source & Age (years) & $\begin{array}{c}\text { Test } \\
\text { Replication }\end{array}$ & $\begin{array}{c}\text { Strength } \\
\text { (MPa) }\end{array}$ & $\begin{array}{c}\text { Modulus } \\
\text { (MPa) }\end{array}$ \\
\hline \multirow{5}{*}{ Compression } & Chengqi Roof Wood & 300 & 2 & 27.51 & 1210 \\
& Chengqi Wood Rib & 300 & 2 & 32.53 & 395 \\
& Chengqi Wood Rib II & 300 & 2 & 33.58 & 2092 \\
& Chengqi Bark Rib & 300 & 2 & 17.12 & 363 \\
& Fuxing Floor Wood & exposed & 8 & 30.17 & 1572 \\
& Hongkeng Bamboo & exposed & 3 & 76.11 & 2069 \\
\multirow{5}{*}{ Tension } & Chengqi Wood Rib & 300 & 5 & 11.77 & 240 \\
& Hongkeng Bamboo & exposed & 2 & 30.70 & 3194 \\
\hline
\end{tabular}

Table 2 shows the tension and compression properties of the wood and bamboo samples collected. A few observations can be drawn from Table 2: 1) Materials of varying strength/stiffness were used as wall ribs, including dry barks from tree. As compared to rammed earth (Table 1), these materials (even aged) are still $\sim 8$ to 35 times stronger than rammed earth (a ratio, equivalent to steel/FRP rebar in concrete), but also $\sim 6$ to 35 times stiffer (not the case with steel/FRP rebar in concrete); 2) Bamboo is a few times stronger and stiffer than timber; and 3) Stiffness is seen with much higher degradation than strength for both unexposed and exposed (to natural aging) specimens. For reference, bamboo has a typical tensile strength of $150 \mathrm{MPa}$ and modulus of $18 \mathrm{GPa}$ while Chinese fir has a typical tensile strength of $35 \mathrm{MPa}$ and modulus of $10 \mathrm{GPa}$. The modulus of elasticity data of these aged timber and bamboo specimens along with the rammed earth modulus data (Table 1) are used in the FE analysis.

\subsection{Determining Volume Fraction of Reinforcement in Rammed Earth Wall}

To estimate the volume of reinforcements in a typical rammed earth wall (known as the fiber volume fraction for a fiber reinforced polymer composite), an easy-to-access cross section of rammed earth wall was identified with pultruding bamboo strips as wall ribs (Fig. 10, right). Dimensions of the exposed wall ribs, their spacing, and the wall thickness were field-measured and used to compute the volume of reinforcement for this particular wall. Based on the samples collected, the wooden sticks were typically round with about $4 \mathrm{~cm}$ in diameter, which results in a fiber cross section of $12.56 \mathrm{~cm}^{2}$ while bamboo strips were in near-rectangular shape with dimensions typically around $1.25 \mathrm{~cm} \times 2.5 \mathrm{~cm}$, which results in a fiber cross section area of $3.13 \mathrm{~cm}^{2}$. Assuming that the same spacing was used for both wood reinforcement and bamboo reinforcement as exhibited by the exposed wall ribs in Fig. 10 (right), then the volume fraction comes out to be $6.7 \%$ for wood reinforcement and $1.8 \%$ for bamboo reinforcement. Using the strength and stiffness data of constituent materials along with the above volume fraction Fig.s, the strength and modulus of elasticity for a reinforced rammed earth wall can be calculated using the Rule of Mixture. The average compression properties of rammed earth walls with and without reinforcements are listed in Table 3. 




Fig. 10. Eroded earth wall exposing wooden sticks (left) and a wall section exposing bamboo strips as reinforcements (right)

Table 3. Rammed earth wall compression properties with and without reinforcements

\begin{tabular}{cccccc}
\hline $\begin{array}{c}\text { Reinforcement } \\
\text { Type }\end{array}$ & $\begin{array}{c}\text { Volume } \\
\text { Fraction }(\%)\end{array}$ & $\begin{array}{c}\text { Reinforcement } \\
\text { Strength (MPa) }\end{array}$ & $\begin{array}{c}\text { Reinforcement } \\
\text { Modulus (MPa) }\end{array}$ & $\begin{array}{c}\text { Earth Wall Strength } \\
(\mathrm{MPa})\end{array}$ & $\begin{array}{c}\text { Earth Wall } \\
\text { Modulus (MPa) }\end{array}$ \\
\hline None & $\mathrm{n} / \mathrm{a}$ & $\mathrm{n} / \mathrm{a}$ & $\mathrm{n} / \mathrm{a}$ & 2.52 & 72.81 \\
Wood & 6.70 & 27.74 & 950 & 4.21 & 131.58 \\
Bamboo & 1.80 & 76.11 & 3194 & 3.85 & 129.00 \\
\hline
\end{tabular}

\section{On the Wall Crack of Huanji Tulou}

\subsection{How the Crack Was Created?}

Finite element modeling approach was used to understand how the crack of Huanji Tulou was created. The formation of crack can be related to the opening of the fourth floor window where a timber lintel was used to direct the structural loads including the weight of rammed earth wall and other loads, away from the window. A close view of the crack in relation to the lintel is shown in Fig. 11 (left).

The FE analysis was carried out using the structural engineering analysis and design program RISA-2D developed by RISA Technologies, LLC. A FE model consisting of the window and lintel along with earth wall was created with the following dimensions: window $70 \mathrm{~cm}$ in width $\mathrm{x} 100 \mathrm{~cm}$ in height, timber lintel $110 \mathrm{~cm}$ in length, wall thickness $180 \mathrm{~cm}$, wall height above the lintel $275 \mathrm{~cm}$. Larch wood properties were used for lintel. Since the modulus of elasticity for the earth sample of Huanji Tulou was not obtained, instead the lowest value among all the earth samples tested, $11.76 \mathrm{MPa}$, was used as the most conservative modulus. Assuming rammed earth of a density of $1600 \mathrm{~kg} / \mathrm{m}^{3}$, a distributed dead load due to the weight of the rammed earth wall on the top of the lintel was computed to be $7920 \mathrm{~kg} / \mathrm{m}$. A pictorial reference of how the lintel would act under dead load can be seen in Fig. 11 (right). Note that the deflection of the lintel due to dead load is magnified by a factor of ten in order to effectively display the behavior of the lintel.

As shown in Fig. 11 (right), Step one shows the dead load of the rammed earth acting on the top portion of the lintel, resulting in a positive bending moment as shown by Step two. This positive bending moment makes the lintel to bend downwards in the center and slightly upwards at the ends. The upward deflection that is experienced at the ends of the lintel creates a compression action in the vertical direction of the rammed earth wall. The rammed earth wall would most likely not be in pure compression and would tend to buckle either inwards or outwards. This buckling would then create a tension action in the horizontal direction of the rammed earth. Step three shows the tension action that 
is experienced within the rammed earth wall and then the predicted crack pattern due to tension failure of the material. Since rammed earth, similar to concrete, is much weaker in tension than compression, tensile splitting will be the primary failure mode. The image shown in Fig. 11 (left) appears to support the above analysis.
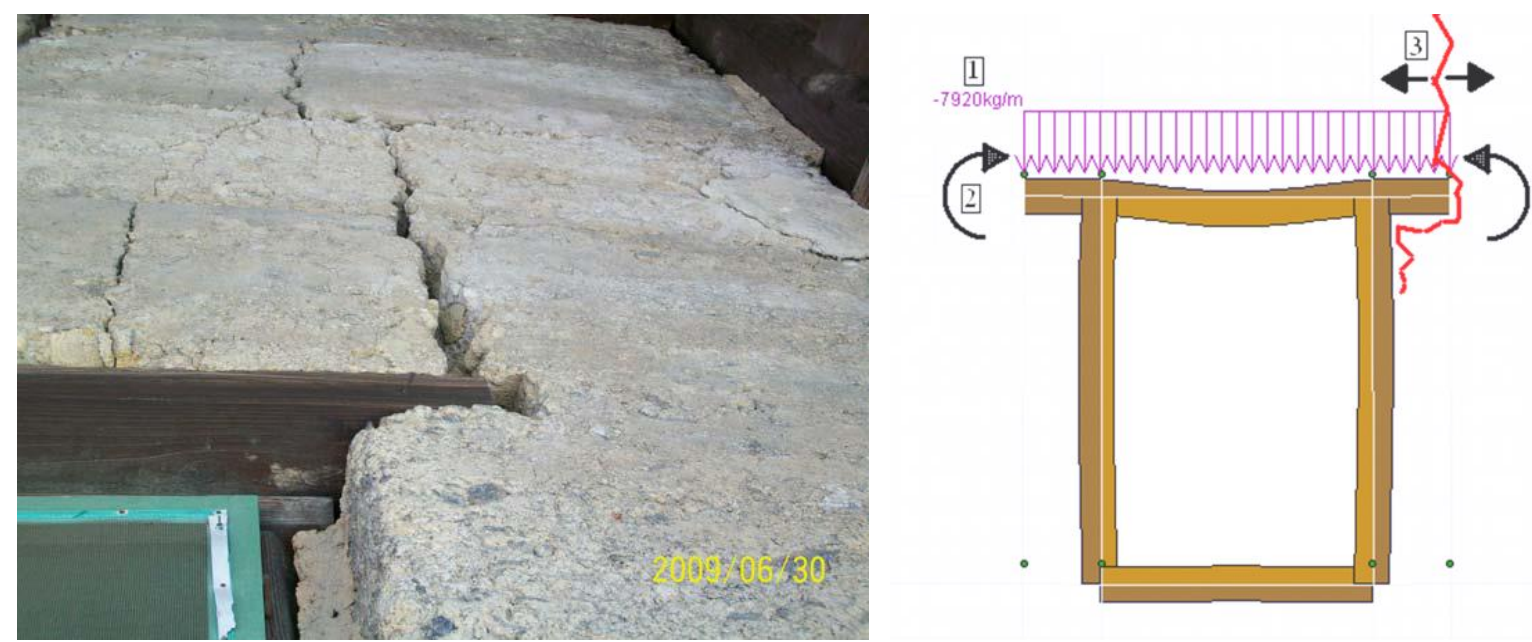

Fig. 11. The crack and cavity at lintel end (left) and Lintel behavior under the dead load (right)

Failure analysis using RISA program was performed using the maximum principle stress theory also known as the Rankine stress theory [7]. A stress distribution from the analysis, due to the above described dead load is shown in Fig. 12. Note that in the RISA structural analysis, tension is labeled as a negative value and compression is labeled as a positive value; $\sigma 1$ (Sig1) represents the stress in the vertical direction of the wall while $\sigma 2$ (Sig2) represents the stress in the horizontal direction of the wall. The stress distribution proves that the lintel does create a compression action on the rammed earth wall in the vertical direction and also shows where the maximum compressive stress is located and thus where most buckling action is likely to occur. This analysis basically verifies the three-step hypothesis described above and predicts a probable crack path (where the greatest stress occurs) in agreement with the reality. However, the dead load alone is not enough to create cracking in the rammed earth wall. As shown in Fig. 12, the greatest stress from the model analysis is $2.66 \mathrm{KPa}(0.386 \mathrm{psi})$.

External loads that will increase the stresses experienced around the lintel and in the rammed earth wall can come from strong winds as well as seismic activity. The model was further analyzed under an earthquake induced horizontal load of $102,150 \mathrm{~kg}$ (225 kips). This horizontal load as an equivalent shear load that is experienced by an earthquake was applied $4 \mathrm{~m}$ below the lintel. To allow the model to move as desired, the bottom restraints were released to mimic the base of the structure moving together with the ground. One support was added at the top of the structure to mimic resistance against the motion. Under these boundary conditions, this model involves a second mode shape, meaning that there will be two different curvatures in the deflection shape. As a matter of fact, during an earthquake, a structure will experience more than one mode of deflection. Thus multiple mode analysis is needed to reflect what could occur to the Tulou during seismic activity.

Stress distribution charts under the above horizontal load, similar to Fig. 12, are obtained. The simulation results show that under influence of $102,150 \mathrm{~kg}$ horizontal load, the maximum compressive stress $\left(\sigma_{1}\right)$ at the ends of the lintel would be increased to $1.03 \mathrm{MPa}(149 \mathrm{psi})$, while the maximum tensile stress $\left(\sigma_{2}\right)$ at the ends of the lintel would be $1.12 \mathrm{MPa}(162 \mathrm{psi})$. These stresses are close to the failure stresses of the rammed earth walls (Table 1). Note that rammed earth is weaker in tension than compression and hence failure (cracking) of an earth wall will first occur due to high stresses in the $\sigma_{2}$, i.e. tension splitting in the horizontal direction instead of compression failure in the vertical direction. 
Hence, the crack would have begun at the end of lintel and propagated upwards and downwards along the path of greatest stress, as reflected by the Probable Crack Path line in Fig. 12. The modeling performed using RISA is viable to predict how the crack occurs and grows under an earthquake. The analysis appears to have captured the essential features of the crack of Huanji Tulou.

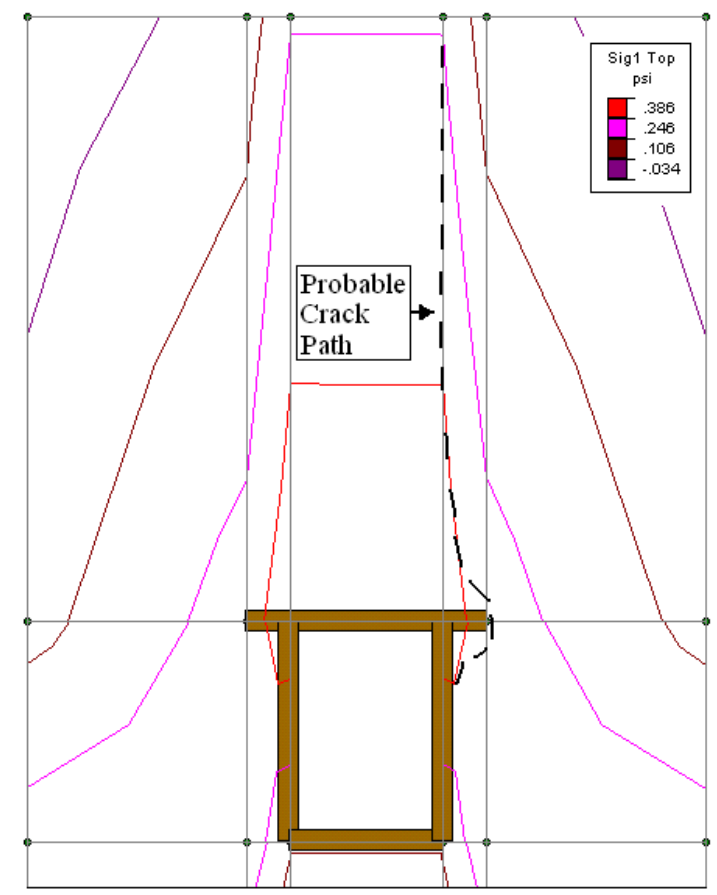

Fig. 12. Stress distribution around Lintel area due to the dead load of rammed earth wall

It is interesting to note that the rammed earth wall of Huanji Tulou was found without any reinforcements. As shown in Table 3, on average, the reinforced rammed earth wall would be $68 \%$ stronger and $82 \%$ stiffer than the corresponding unreinforced earth wall. If the rammed earth wall of Huanji Tulou were reinforced with wall ribs, such cracking most likely would not have occurred. This might explain why other Hakka Tulou, with reinforced earth walls, survived from the earthquakes even without cracking.

\subsection{Has the Crack Self Healed?}

If the crack, as reported, were originally $20 \mathrm{~cm}$ in width and self-healed to the present 5 to $10 \mathrm{~cm}$, there should be some kind of self-healing process that could be understood scientifically. The authors first investigated the possible effect of thermal expansion and contraction of the massive rammed earth wall of Huanji Tulou. This objective was achieved through FE modeling using RISA 3D structural engineering analysis and design software.

The actual dimensions of Huanji Tulou were used to build a FE Tulou model that consisted of circular earth walls without inner timber structures but included the reported $3 \mathrm{~m} \mathrm{x} 20 \mathrm{~cm}$ crack. A fixed connection at the base and a pinned connection at the top of each wall were applied as boundary conditions. Since the modulus of elasticity for the earth sample of Huanji Tulou was not obtained, again, the lowest value among all the earth samples tested, $11.76 \mathrm{MPa}$, was used. A thermal expansion coefficient of a clay brick of $3.3^{*} 10^{-6} \mathrm{in} / \mathrm{in} /{ }^{\circ} \mathrm{F}$ was used. Then a $70^{\circ} \mathrm{F}$ temperature variation thermal load was applied across the entire model. The simulation indicates that under the cooler thermal load, the crack would close by over half at the most extreme point, i.e. $10.8 \mathrm{~cm}$, yielding an opening of $9.2 \mathrm{~cm}$. 
However, this temperature effect cannot be viewed as self-healing, because the crack would resume once the thermal load is removed.

Autogenous healing has been researched for several decades in common building materials such as concrete. Current research on autogenous healing of concrete has mostly portrayed the healing of small cracks or micro cracks experienced in concrete systems. The key ingredient to this healing process is lime. As cracks appear in a concrete system, water infiltrates the cracks and dissolves any lime that it may come in contact with. The dissolved lime is then taken to the surface of the crack where it carbonates and begins to heal the crack [14]. Such a healing mechanism would not work in the case of Huanji wall crack, not to mention that EDS chart of Huanji earth sample shows no sign of calcium (Fig. 8).

A third hypothesis was that a partial healing of the crack might be enabled by the extensive use of internal reinforcements in the rammed earth wall. When the earthquake induced load created an opening on the wall, this would generate a high stress area. Facilitated by the internal reinforcement, a stress relaxation might occur, leading to self-healing of crack. However, the authors discovered during field study that Huajian Tulou was not reinforced with any wood strips.

Considering the scale of this crack (a strain of $0.15 \%$ ), the authors would doubt if any self-healing process took place at all. The fame of Huanji Tulou as the strongest Tulou should be interpreted as follows: Even though Huanji Tulou had such a large cross-thickness crack, it is still structurally sound and stands the test of time.

\section{Structural Response of Huanji Tulou under Earthquake Loads}

The structural response of Huanji Tulou under an earthquake load was further evaluated through FE modeling using RISA 3D program that has packed with the most current steel, concrete, and timber design codes, allowing tackling multi-material model analysis. Earthquake load was applied as per the simplified lateral force analysis procedure provided by ASCE-7 [15]. This design code is typically used for frame type structures no higher than three stories as this code focuses on base shear rather than the dynamic response from an earthquake. The base shear from an earthquake is of primary concern for short structures while dynamic effects for higher structures. Due to the thickness of the earth walls and resulting high mass, it was assumed that a simplified lateral force analysis would be sufficient for Huanji Tulou. By distributing the base shear that results from a design earthquake for the region, throughout the four floors of the structure, one can analyze the stress induced into the rammed earth walls.

Initially, only the thick rammed earth walls and their self-weight were considered during modeling. As discussed previously, the lowest modulus of $11.76 \mathrm{MPa}$ among all the earth samples tested was used to present the most conservative case. Then the effect of wall reinforcements on the structural response was considered. Using the average modulus of wood reinforcement $(950 \mathrm{MPa})$ at a volume fraction of $6.7 \%$, the rule of mixture gives a modulus of $74.62 \mathrm{MPa}$ for the reinforced earth wall. Finally, the rammed earth walls (with a modulus of $11.76 \mathrm{MPa}$ ) combined with inner timber structures (floor systems) were modeled to better reflect the response of actual Tulou buildings. In the model, the timber beams and columns are round with a diameter of $20 \mathrm{~cm}$ and assigned with the material properties of Douglas Fir [7]. The above three scenarios are summarized in Table 4.

There are two important equations used in the simplified lateral force analysis [15]:

$$
\begin{aligned}
& V=\frac{F S_{\mathrm{DS}}}{R} W \\
& S_{\mathrm{DS}}=\frac{2}{3} F_{\mathrm{a}} S_{\mathrm{S}}
\end{aligned}
$$


Equation 1 calculates the base shear ' $\mathrm{V}$ ' from a design earthquake and can be distributed throughout each floor of the structure by changing ' $W$ ' to be the effective seismic weight of the structure at that floor of interest. ' $R$ ' is the response modification coefficient which is taken as 1.5 for a bearing wall system made of ordinary plain masonry walls. This factor was chosen as it most resembled the conditions of a rammed earth wall. ' $\mathrm{F}$ ' is a factor that depends on the structure height and is taken as 1.2 in this study. ' $\mathrm{S}_{\mathrm{Ds}}$ ' is a design-spectral response acceleration at short periods, $5 \%$ damped, which is calculated using Equation 2. ' $\mathrm{F}_{\mathrm{a}}$ ' is the short period site coefficient at 0.2 seconds which can be found in a table knowing both ' $\mathrm{S}_{\mathrm{s}}$ ' and site class of the area of interest. Since the site class is unknown, ASCE7 states that one can classify the site as class D unless geotechnical data determines that class $\mathrm{E}$ or $\mathrm{F}$ are present. ' $\mathrm{S}_{\mathrm{s}}$ ' is the mapped spectral response acceleration, $5 \%$ damped, at a period of 1 second.

The Global Seismic Hazard Assessment Program (GSHAP) has compiled seismic maps from all around the world. The seismic map for China was created by the Chinese government in 1992 and shows peak ground acceleration which has a $10 \%$ chance of exceeding marked intensities in 50 years [16]. From the seismic China map, the Peak Ground Acceleration (PGA) for the Fujian Province varies from $0.8-1.6 \mathrm{~m} / \mathrm{s}^{2}$. This map also coincides with an earthquake report on China performed by Lanbo Liu [17], in which he states no major post Paleozoic tectonic activity has been found in the region and thus seismicity for the Fujian province is low. No maps of spectral response acceleration for the China region were found. ASCE-7 allows one to convert PGA to the mapped spectral response acceleration, ' $\mathrm{S}_{\mathrm{s}}$ ', by simply multiplying the PGA by a factor of 2.5 . To be conservative, a PGA of $1.6 \mathrm{~m} / \mathrm{s}^{2}$ was multiplied by 2.5 to get an ' $\mathrm{S}_{\mathrm{s}}$ ' value of 4 . ASCE-7 states that ' $\mathrm{S}_{\mathrm{s}}$ ' need not be taken higher than a value of 1.5 which results in a short period site coefficient, ' $F_{a}$ ', of 1.0. By plugging in the ' $\mathrm{S}_{\mathrm{s}}$ ' and ' $\mathrm{F}_{\mathrm{a}}$ ' values of 1.5 and 1.0 into Equation 2, one gets a ' $\mathrm{S}_{\mathrm{DS}}$ ' value of 1.0. Applying ' $\mathrm{S}_{\mathrm{DS}}$ ' value to Equation 1 yields Equation 3:

$$
V=0.8 W
$$

Equation 3 calculates the base shear force for the entire structure. Huanji Tulou has a total weight of $7.49 \times 10^{6} \mathrm{~kg}$, resulting in a total base shear force of $5.99 \times 10^{6} \mathrm{~kg}$. The vertical distribution of the force for each floor can be computed using Equation 4:

$$
F_{\mathrm{x}}=\frac{w_{\mathrm{x}}}{W} V
$$

where ' $w_{\mathrm{x}}$ ' represents the portion of the effective seismic weight of the structure. Since Huanji Tulou has 4 evenly spaced floors, the force per floor is $1.5 \times 10^{6} \mathrm{~kg}$. Divivided by 16 , which is the number of nodes used to create the circular model, gives the lateral load per node to be $93,645 \mathrm{~kg}$. These loads are applied simultaneously on all 16 nodes for each floor in order to represent the effects of a maximum design earthquake that can be expected in the Fujian Province.

Table 4. The effect of model composition on the max base deformation and compressive/tensile stress

\begin{tabular}{lcccccc}
\hline $\begin{array}{c}\text { Model } \\
\text { Composition }\end{array}$ & $\begin{array}{c}\text { Wall } \\
\text { Reinforcement }\end{array}$ & $\begin{array}{c}\text { Inner Timber Wall Modulus } \\
\text { Structure }\end{array}$ & $\begin{array}{c}\text { Max } \\
\text { Deflection } \\
(\mathrm{MPa})\end{array}$ & $\begin{array}{c}\text { Max Vertical } \\
\text { Stress } \\
\left(\sigma_{1}, \mathrm{KPa}\right)\end{array}$ & $\begin{array}{c}\text { Max Horizontal } \\
\text { Stress } \\
\left(\sigma_{2}, \mathrm{KPa}\right)\end{array}$ \\
\hline 1) Earth Wall & No & No & 11.76 & 250 & 972 & 972 \\
2) Earth Wall & Yes & No & 74.62 & 39 & 153 & 153 \\
3) Earth Wall & No & Yes & 11.76 & 20 & 100 & 100 \\
\hline
\end{tabular}

Again, stress analysis was performed using the maximum principle stress theory. The results under three modeling schemes are summarized in Table 4. In Table 4, the maximal deflection was taken at the top of the structure; the maximal vertical stress is compression stress and the maximal horizontal 
stress is tensile stress. Fig. 13 shows the stress distribution in the vertical direction of the wall $\left(\sigma_{1}\right)$, from the model that included the inner wooden structures (Case 3$)$. The horizontal stress $\left(\sigma_{2}\right)$ distribution is simply a mirror image of the $\sigma_{1}$ stress distribution. Table 4 shows that for the Case 1 that considers the rammed earth walls alone, the maximum stress is $972 \mathrm{KPa}(141 \mathrm{psi})$ near the base of the Tulou, producing a deformation of $250 \mathrm{~cm}$ at the top; For the Case 2, when the rammed earth walls are reinforced with wood sticks, the maximal stress and deformation are dramatically reduced to $153 \mathrm{KPa}$ (22.1 psi) and $39 \mathrm{~cm}$, respectively; Under Case 3, when the rammed earth walls of the same modulus as Case 1 are combined with inner timber structures, the maximum stress is only $100 \mathrm{KPa}$ (14.6psi) at the base of the structure, producing a deformation of only $20 \mathrm{~cm}$. For a Tulou model that has reinforced earth walls combined with inner timber structures, the maximal stress and deformation will be further reduced to $16 \mathrm{KPa}(2.28 \mathrm{psi})$ and $3.1 \mathrm{~cm}$, respectively. The results clearly demonstrate that the large mass of outer rammed earth walls together with the integrity of inner wooden structures is a primary contributing factor for the excellent earthquake resistance of Hakka Tulou. Both round and square Tulous have performed outstandingly under earthquake loads.

Hence, Hakka Tulou construction makes the structures strong. The rammed earth walls are high in mass and volume which causes material stresses to be kept low and away from failure zones. The thick rammed earth walls integrated with inner wooden floor structures resist the design earthquake very well. As a matter of fact, the rammed earth wall is built in a taper design with the base much thicker and the top thinner, instead of an uniform thickness from the base to top as used in the model. The tapered wall design not only offers the wall with better structural stability, but also higher earthquake resistance, more efficient use of materials, and optimal thermal comfort.

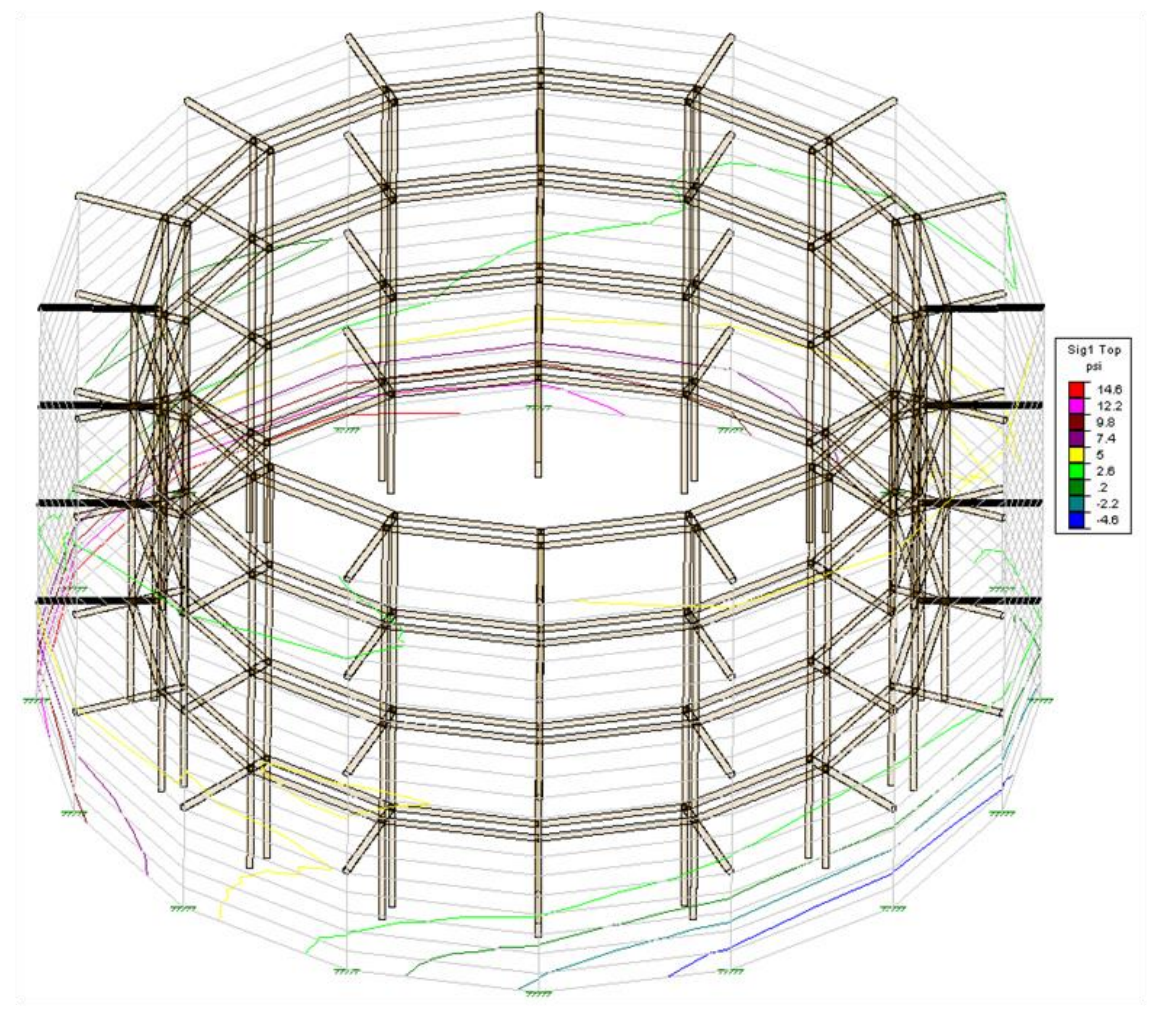

Fig. 13. Stress distribution of Huanji Tulou with inner wooden systems under a design earthquake load

\section{Conclusions}

In this paper, material characterization including scanning electron microscopy and mechanical evaluations of field collected earth and timber samples was carried out. The compressive strength and 
modulus of five Hakka Tulou of varying ages are reported. The results demonstrate that the rammed earth walls of Hakka Tulou are strong and durable, even though each wall varies in composition from others. More interestingly, both the strength and modulus data appear to show a trend that Hakka earth wall becomes stronger and harder with time. Finite element modeling was conducted to simulate the material and structural responses of Hakka Tulou under thermal and earthquake loads for a better understanding of their outstanding earthquake resistance. Huanji Tulou has a large crack on its rammed earth wall reportedly due to a strong earthquake in 1918. Local people claimed that crack was selfhealed and thus Huanji was known as the strongest Tulou. After careful investigation, the authors found no evidences of self-healing process to back up that claim. The rammed earth wall of Huanji Tulou was found without reinforcements. The computer modeling has successfully simulated why and how the crack was initiated and further developed under an earthquake induced load. The FE modeling has demonstrated that the Hakka Tulou does offer superior earthquake resistance because of its unique rammed earth wall construction integrated with inner timber floor structures, making the structures strong and durable.

\section{Acknowledgments}

The authors would like to thank Dr. Ying Lei and his team at Xiamen University for assistance with some laboratory testing. Liang is also indebted to Dr. Ken P. Chong, former NSF Program Director for his enthusiastic support and useful discussion during this study. In addition, support and assistance during our field study in the summer of 2009 from Local and County Government Officials of Yongding of Fujian province of China, many individuals including officers from Tulou Administrations, and owners of Hakka Tulou studied is sincerely acknowledged.

\section{Funding Statement}

This study was supported by NSF-US (CMMI \#0908199).

\section{Conflict of Interest}

The authors declare no conflict of interest.

\section{References}

[1] Liang RF, Hota G, Lei Y, Li YH, Stanislawski D, Jiang YQ. Nondestructive evaluation of historic Hakka rammed earth structures. Sustainability, 2013, 5, 298-315.

[2] Kinser R. Deltec homes: The original green builder of unique, energy efficient circular homes: http://www.deltechomes.com/_(accessed on 5 August 5, 2021)

[3] UNESCO. WHC advisory body evaluation report No.1113: Fujian Tulou (China), 2008: http://whc.unesco. org/en/list/1113/ (accessed on 5 August 5, 2021)

[4] UNESCO, Nomination document of Hakka Tulou for inscription on World Heritage List, 2008: http://whc.unesco.org/en/list/1113/_(accessed on 19 October 2012)

[5] Chinadaily. 'Black UFOs' in Fujian mountains, 2007: http://www.chinadaily.com.cn/ezine/200705/16/content_873463_2.htm_(accessed on 5 August 5, 2021)

[6] Visit Our China, Huanji Building: https://www.visitourchina.com/xiamen/attraction/huanji-building.html (accessed on 5 August 5, 2021)

[7] Stanislawski D. Mechanical response and finite element modeling of Hakka Tulou rammed earth structures, MSCE Thesis, West Virginia University, Morgantown, WV, 2011

[8] Lowe KD. Heaven and earth—sustaining elements in Hakka Tulou. Sustainability, 2012. 4, 2795-2802.

[9] Zhou CB, Liang Y. Summary on techniques of rammed earth wall, Proceedings of Int. Workshop on Rammed Earth Materials and Sustainable Structures, Xiamen University, China, Oct 28-31, 2011, pp399404. 
[10] Su ZQ. Construction technology of sustainable Yongding Hakka Tulou. Presented at Int. Workshop on Rammed Earth Materials and Sustainable Structures, Xiamen University, China, Oct 28-31, 2011.

[11] Rammed earth engineering specifications, Rammed Earth Solar Homes, Inc. Oracle, AZ. http://www.ramm edearthhomes.com/technical.htm (accessed on 10 November 2013)

[12] Ostrowski J, Ostrowski H, Li XY, Ueda M. Hakka eco-village study tour report. 28 Sept 2007.

[13] Yang F, Zhang B, Ma Q. Study of sticky rice-lime mortar technology for the restoration of historical masonry construction, Acc. Chem. Res., 201043 (6), pp 936-944.

[14] Rhydwen R. Hemp, in Advanced environmental and energy studies B3 (2007): 38. University of East London. Web. 25 May 2010

[15] ASCE7. Minimum design loads for buildings and other structures, Chapter $11 \&$ 12, 2005. p.109-42. Purdue University.

[16] Zhang P, Yang ZX, Gupta HK, Bhatia SC, Shedlock KM. Implementation of global seismic hazard assessment program (GSHAP) in continental Asia, 1999. Web. 29 June 2010. http://www.seismo.ethz.ch/s tatic/GSHAP/eastasia/eastasia.html_(accessed on 19 October 2012)

[17] Liu L. Stable continental region earthquakes in South China. Pure and Applied Geophysics, 2001, 158: 1583-611. 